\title{
Minimally invasive saphenous vein harvesting using the mayo vein harvester. An alternative to endoscopic vein harvesting?
}

\author{
Jeremy Chan ${ }^{1}$, Harry Smith ${ }^{2}$, and Tracey Cox ${ }^{3}$ \\ ${ }^{1}$ University Hospital of Coventry and Warwickshire \\ ${ }^{2}$ University Hospital of Wales Healthcare NHS Trust \\ ${ }^{3}$ University Hospitals Coventry and Warwickshire NHS Trust
}

November 23, 2020

\begin{abstract}
The Great saphenous vein (GSV) has been widely used as a conduit for Coronary artery bypass grafting. The GSV can be harvested using the open or minimally invasive technique. Minimally invasive techniques are growing in popularity due to better cosmetic and wound infection outcomes. The most widely used method in minimally invasive technique is via endoscopic approach. However, the cost of endoscopes and training curve can limit its use. We describe an alternative minimally invasive technique using a mayo vein harvester with a considerably lower cost, and a smoother learning curve. Keywords: Saphenous vein harvesting, Mayo vein harvester, Minimally invasive
\end{abstract}

\section{Hosted file}

2Minimally_invasive_saphenous_vein_harvestingusingthe_mayovein_harvester.pdf available at https://authorea.com/users/378111/articles/494674-minimally-invasive-saphenous-veinharvesting-using-the-mayo-vein-harvester-an-alternative-to-endoscopic-vein-harvesting 